\title{
Immunohistochemical Expression of p16INK4A in The Lesions of Uterine Cervix
}

\author{
Niharika Rawat ${ }^{1}$ and Shivapriya $\mathbf{R}^{2 *}$ \\ ${ }^{1}$ Department of Pathology, Peoples college of Medical sciences and Research Centre, Bhopal \\ ${ }^{2}$ Department of Pathology, KMCH Institute of Health Sciences and Research, Coimbatore
}

\begin{abstract}
Background: Cervical cancer is the major cause of cancer deaths among women. Globally, around 5,70,000 new cases of cervical cancer and 3,11,000 deaths occurred in the year 2018. In India, Cervical cancer is a leading cause of cancer related mortality among women and the number of deaths is 60,000 per year among 97,000 diagnosed patients, especially those from lower socioeconomic group. Human Papilloma Virus (HPV) plays a crucial role in causing cervical dysplasia. This is done by upregulating p16INK4A, a cyclin dependent kinase inhibitor through interaction with cellular regulatory proteins. Hence p16INK4A can be used as a biomarker, since it is directly related variable for the presence of HPV. This study was conducted to evaluate the expression of p16INK4A in benign, premalignant and malignant cervical lesions and to assess its utility in diagnosing and grading cervical lesions.
\end{abstract}

Methods: A total of 80 cervical specimens categorized histopathologically into nonspecific cervicitis, low grade squamous intraepithelial neoplasia (LSIL), high grade squamous intraepithelial neoplasia (HSIL) and squamous cell carcinoma cervix were included in this prospective study of one-year duration. Immunohistochemical study of p16INK4A were interpreted qualitatively and semi-quantitatively by Allred scoring system (0 to 8 points) which measures the proportion of stained cells and intensity of staining of cells. The collected data were statistically analyzed by ANOVA and chi square test.

Result: Qualitative method showed absence of p16INK4A expression in all nonspecific cervicitis. 16.7\% (2/12) LSIL, 100\% (12/12) HSIL and $100 \%$ (28/28) squamous cell carcinoma cases showed p16INK4A positivity. Allred scoring of p16INK4A showed 66\% (8/12) HSIL and $85.7 \%$ (24/28) squamous cell carcinoma cases with score 3 positivity. Hence high-grade lesions showed higher expression of this marker.

Conclusion: IHC expression of p16INK4A showed increasing degree of expression from benign to premalignant and malignant lesions suggesting its diagnostic and prognostic value in the cervical cancer management.

Keywords: p16INK4A, Intraepithelial Neoplasia, Cervix Carcinoma

\section{Introduction}

Worldwide, cervical carcinoma is the fourth-most common cause of cancer and fourth common cause of death in women. ${ }^{[1]}$ Every year, cervical cancer is diagnosed in about 5,00,000 women globally and is responsible for more than 2,80,000 deaths annually. ${ }^{[2]}$ In India, Cervical cancer is a leading cause of cancer related death among women, especially those from lower socioeconomic group contributing to about one third of total world population. ${ }^{[2]}$ Human papilloma virus is the prime cause for carcinoma cervix and its prevalence among cervical cancer patients varied from $87.8 \%$ to $96.67 \%{ }^{\left[{ }^{[3]}\right.}$ Molecular studies have shown that HPV 16 and 18 are most common oncogenic types involved in causing carcinoma cervix. HPV infection of cervix is sexually transmitted. Young and sexually active women are at highest risk for HPV infection and preinvasive cervical neoplasia.

Carcinoma cervix is known to develop from premalignant lesion, intraepithelial neoplasia. It takes nearly 5 to 15 years to progress to invasive carcinoma. ${ }^{[4]}$ Hence it is very essential to identify precancerous lesion for appropriate treatment. No form of malignancy better documents the most remarkable benefits of effective screening, early diagnosis, and curative therapy than does the carcinoma of cervix. ${ }^{[4]}$ However detection and interpretation of HPV infection in cervical specimens are difficult. Hence indirectly assessing the presence of HPV infection by analyzing a step-in pathogenesis of HPV cell cycle is of utmost importance.

Various studies have highlighted the role of p16INK4A as an excellent marker of cervical carcinoma. Its expression is associated with the progression of disease. It is directly related to the presence of $\mathrm{HPV} .^{[5]}$ p16INK4A belongs to cyclin-dependent kinase Cdk4/6 inhibitors. It is encoded by tumor suppressor gene INK 4A. It has an important role in the regulatory pathway $\mathrm{Cdk}-\mathrm{Rb}-\mathrm{E} 2 \mathrm{~F}$. The protein product of the gene, p16INK4A, prevents $\mathrm{pRb}$ phosphorylation by inactivating cyclin dependent kinase $\mathrm{Cdk} 4 / 6$. pRb keeps binding E2F transcription factors and rests the cell in G1 phase and does not pass DNA for replication. ${ }^{[6]}$ In 
HPV related cervical lesions, HPV derived oncoprotein E7 interacts with $\mathrm{pRb}$ and inactivates it leading to the disruption of the regulatory pathway Cdk-Rb-E2F. Inactivated $\mathrm{pRb}$ passes the cell cycle to the checkpoint G1/S without any inhibition. As a response to this event, an overexpression of p16INK4A occurs [FIGURE 1]. ${ }^{[7]}$ Thus, p16INK4A protein can be a marker of premalignant and malignant cervical epithelial cells. ${ }^{[8]}$ Hence p16INK4A expression can be used as a biomarker, since it serves as a directly related variable for the presence of HPV. It can add a significant diagnostic material in the diagnosis of CIN lesions. ${ }^{[9]}$

\section{Objectives of The Study}

1. To evaluate the expression of marker p16INK4A in benign, premalignant and malignant cervical lesions.

2. To assess the utility of p16INK4A marker in diagnosing and grading cervical lesions.

\section{Materials and Methods}

This Prospective study was conducted in the ANONYMIZED from May 2015 to April 2016. Ethical clearance for the study was obtained from the institutional Ethical committee.

\section{Inclusion Criteria}

- Cervical biopsies from women in ages ranging from 20 years to 70 years.

- Women with Colposcopy findings suggestive of cervical abnormality are included in the study.

\section{Exclusion Criteria}

- Patients with the history of HPV vaccination

- Patients with recurrent cervical cancer

- Patients under treatment for cervical malignancy are excluded from the study

A total sample of 80 cervical biopsies were analysed of which 28 cases were of invasive squamous cell carcinoma, each 12 cases of low grade squamous intraepithelial lesion and high grade squamous intraepithelial lesion and 28 cases were of nonspecific cervicitis. They were categorized based on their histomorphological features in haematoxylin and eosin stained sections.

Cervical biopsies showing dense chronic inflammatory cell infiltrate predominantly composed of plasma cells and few lymphocytes in superficial cervical stroma are categorized under non-specific cervicitis. ${ }^{[10]}$ In our study, the premalignant lesions of cervix were classified based on two tier system: low-grade squamous intraepithelial lesions [LSILs] and high-grade squamous intraepithelial lesions [HSILs]. ${ }^{[4]}$. Biopsies showing koilocytic changes in superficial differentiating cells and cells above basal layer show increased nuclear cytoplasmic ratio and increased mitotic activity are categorized as LSIL. ${ }^{[1]}$ and those showing high nuclear cytoplasmic ratio for lower two third and full thickness of epithelial lining and are mitotically active are categorized as HSIL. ${ }^{[1]}$

Cervical carcinoma was classified according to WHO histological classification of invasive carcinomas of uterine cervix. Squamous cell carcinoma of cervix is graded as well differentiated (Grade 1), moderated differentiated (Grade 2) and poorly differentiated (Grade 3) according to Modified Broder system. ${ }^{[12]}$ Well differentiated(Grade 1) show malignant cells with individual cell keratinization, mitotic figures and keratin pearls within tumor nests, Moderated differentiated (Grade 2) show pleomorphic tumor cells with less cytoplasm and larger irregular nuclei. Cell borders are often indistinct. keratin pearls are less common. Mitotic activity is greater than Grade 1 tumors and Poorly differentiated (Grade 3) show primitive tumor cells with hyperchromatic oval nuclei and scant indistinct cytoplasm. Mitosis are common and extensive necrosis is noted. Evidence of keratinization is difficult to identify. Occasionally Grade 3 tumors consists of large pleomorphic cells with bizarre nuclei and abnormal mitotic figures. ${ }^{[12]}$

Formalin fixed and paraffin embedded tissue specimen of cervical biopsies were stained for routine haematoxylin and eosin stain. Sections of four micron thickness were cut and stained for immunohistochemistry with p16INK4A mouse monoclonal antibody (clone E6H4). Immunohistochemistry stained sections were assessed qualitatively and semiqualitatively by Allred scoring system which is based on intensity and proportion of staining of tumor cells.

Intensity and the proportion of staining of cells for p16INK4A were scored according to the following. ${ }^{[13]}$

Table 1: The Allred Score. ${ }^{[13]}$

\begin{tabular}{|l|l|l|l|}
\hline $\begin{array}{l}\text { Intensity } \\
\text { score }\end{array}$ & $\begin{array}{l}\text { Intensity of } \\
\text { staining }\end{array}$ & $\begin{array}{l}\text { PROPOR- } \\
\text { TION } \\
\text { SCORE }\end{array}$ & $\begin{array}{l}\text { Proportion of } \\
\text { cells showing } \\
\text { nuclear and } \\
\text { cytoplasmic } \\
\text { staining }\end{array}$ \\
\hline 0 & $\begin{array}{l}\text { No visible } \\
\text { staining }\end{array}$ & 0 & None \\
\hline $1+$ & Weak staining & $1+$ & Less than $1 \%$ \\
\hline $2+$ & $\begin{array}{l}\text { Moderate } \\
\text { staining }\end{array}$ & $2+$ & 1 to $10 \%$ \\
\hline $3+$ & $\begin{array}{l}\text { Intense } \\
\text { staining }\end{array}$ & $3+$ & 11 to $33 \%$ \\
\hline \multirow{2}{*}{3} & $4+$ & 34 to $66 \%$ \\
\cline { 2 - 4 } & & $5+$ & More than $66 \%$ \\
\hline
\end{tabular}


Allred score is summation of proportion score and intensity score, ranging from 0 to 8 . Since there is only intense staining of tumor cells in this studyhe possible values for Allred score are categorized into score 0 - Allred 0, score 1-Allred 5,6, score 2-Allred 7 and score 3 -Allred 8.

\section{Statistical analysis}

The collected data was tabulated, analysed and statistical analysis was done using SPSS 16.0 version. ANOVA was used to assess the quantitative variables. The Chisquare test was used to assess the differences in categoric variables between groups. The p-value of less than 0.05 was considered statistically significant

\section{Result}

Immunohistochemistry sections of study samples were analysed qualitative and semiquantitative by Allred scoring system. Assessment showed lack of p16INK4A expression with score 0 in all cases of nonspecific cervicitis [Figure 2A,2B]. In low-grade squamous intraepithelial lesions, only $17 \%(2 / 12)$ cases showed strong nuclear and cytoplasmic p16INK4A positivity with score 1 and remaining $83 \%(10 / 12)$ cases were of score 0 [Figure $3 \mathrm{~A}$, 3B]. In High-grade squamous intraepithelial lesions cases, the association of $\mathrm{p} 16 \mathrm{INK} 4 \mathrm{~A}$ expression was positive in all cases with each $17 \%(2 / 12)$ cases of score 1 and 2 and $66 \%(8 / 12)$ cases of score 3 . [Figure 4A, 4B]. Invasive squamous cell carcinoma of cervix showed p16INK4A expression in all cases with $14.3 \%(4 / 28)$ cases of score 2 and $85.7 \%(24 / 28)$ cases of score 3 [Figure 5A,5B]. It showed increasing degree of $\mathrm{p} 16 \mathrm{INK} 4 \mathrm{~A}$ expression from benign to premalignant and to malignant lesions with $p$ value less than 0.05 [Figure 6]. There was increase in score from benign to malignant lesions as per Allred scoring method [Table 2]. Hence high grade lesions of cervix showed high expression of this marker.

Table 2: Correlation of degree of p16INK4A expression with histopathological diagnosis.

\begin{tabular}{|c|c|c|c|c|c|}
\hline \multirow{3}{*}{ Histopathological diagnosis } & \multicolumn{5}{|c|}{ Scoring of p16INK4A expression } \\
\hline & 0 & 1 & 2 & 3 & TOTAL \\
\hline & n (\%) & n (\%) & n (\%) & n (\%) & n \\
\hline Nonspecific cervicitis & $28(100)$ & 0 & 0 & 0 & 28 \\
\hline Low grade squamous intraepithelial lesion & $10(83)$ & $2(17)$ & 0 & 0 & 12 \\
\hline High grade squamous intraepithelial lesion & 0 & $2(17)$ & $2(17)$ & $8(66)$ & 12 \\
\hline Invasive Squamous cell carcinoma & 0 & 0 & $4(14.3)$ & $24(85.7)$ & 28 \\
\hline
\end{tabular}

n-number of patients

Table 3: p16INK4A expression in various studies in cervical biopsies.

\begin{tabular}{|c|c|c|c|c|c|}
\hline $\begin{array}{l}\text { SI. } \\
\text { no. }\end{array}$ & Authors & pathology & $\begin{array}{l}\text { Number of } \\
\text { cases }\end{array}$ & P16INK4a grading followed in the study & $\begin{array}{l}\text { P16INK4a } \\
\text { expression }\end{array}$ \\
\hline \multirow[t]{4}{*}{1} & \multirow[t]{4}{*}{ Present study } & Benign & 14 & \multirow{4}{*}{$\begin{array}{l}\text { More than } 6 \% \text { of epithelial cells show strong } \\
\text { nuclear and cytoplasmic positivity. }\end{array}$} & 0 \\
\hline & & CIN 1 & 6 & & $16.7 \%$ \\
\hline & & CIN 2/3 & 6 & & $100 \%$ \\
\hline & & SCC & 14 & & $100 \%$ \\
\hline \multirow[t]{3}{*}{2} & \multirow{3}{*}{$\begin{array}{l}\text { Fatemeh sari et al } \\
(2013)\end{array}$} & Benign & 24 & \multirow{3}{*}{$\begin{array}{l}\text { Nuclear and continuous diffuse cytoplasmic } \\
\text { staining }\end{array}$} & $1.8 \%$ \\
\hline & & CIN 1 & 4 & & $50 \%$ \\
\hline & & CIN2/3 & 19 & & $100 \%$ \\
\hline \multirow[t]{3}{*}{3} & \multirow{3}{*}{$\begin{array}{l}\text { Reuschenback et al } \\
(2010)\end{array}$} & CIN 1 & 21 & \multirow[t]{3}{*}{ Diffuse nuclear and cytoplasmic expression } & $57.1 \%$ \\
\hline & & CIN 2/3 & 50 & & $86.9 \%$ \\
\hline & & SCC & 46 & & $100 \%$ \\
\hline \multirow[t]{4}{*}{4} & \multirow[t]{4}{*}{ Munhoz et al (2009) } & Benign & 5 & \multirow{4}{*}{$\begin{array}{l}\text { Number of cells showing nuclear and } \\
\text { cytoplasmic staining divided by the number of } \\
\text { cells counted per sample. }\end{array}$} & 0 \\
\hline & & CIN 1 & 12 & & $27.94 \%$ \\
\hline & & CIN 2/3 & 25 & & $61.4 \%$ \\
\hline & & SCC & 12 & & $73.47 \%$ \\
\hline \multirow[t]{2}{*}{5} & \multirow{2}{*}{$\begin{array}{l}\text { Eun Ji Nam, et al. } \\
(2008)^{88}\end{array}$} & CIN 1 & 12 & \multirow[t]{2}{*}{ More than $5 \%$ of cells showing diffuse positivity. } & $16.6 \%$ \\
\hline & & CIN 2/3 & 19 & & $100 \%$ \\
\hline \multirow[t]{4}{*}{6} & \multirow[t]{4}{*}{ Agoff et al(2003) } & Normal & 75 & \multirow{4}{*}{$\begin{array}{l}\text { More than } 25 \% \text { of cells showing nuclear and } \\
\text { cytoplasmic positivity. }\end{array}$} & $13 \%$ \\
\hline & & CIN 1 & 76 & & $46 \%$ \\
\hline & & CIN2/3 & 193 & & $88 \%$ \\
\hline & & SCC & 46 & & $90 \%$ \\
\hline
\end{tabular}




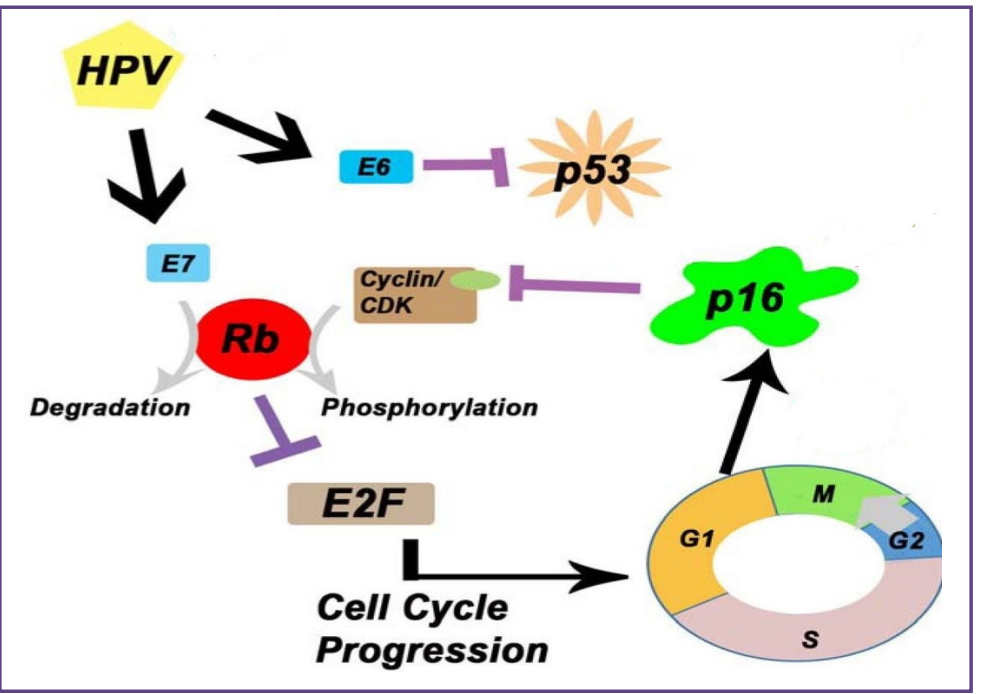

Fig. 1: Functions of p16INK4A.

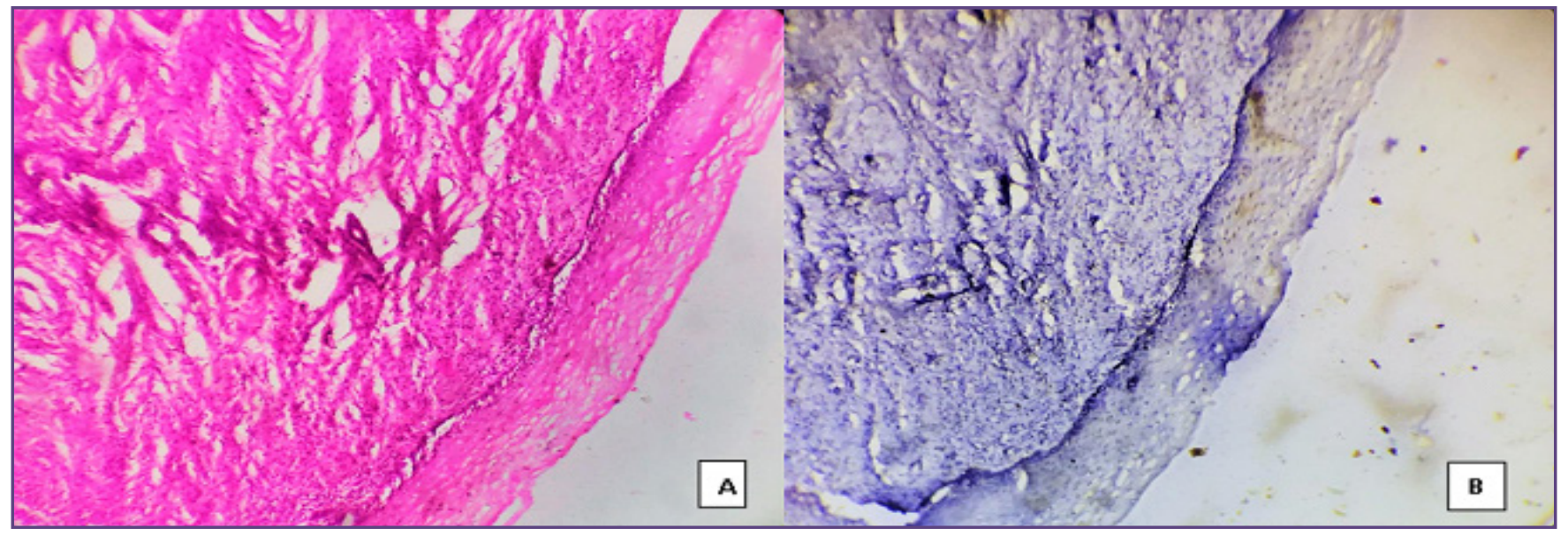

Fig. 2: Nonspecific cervicitis showing lymphoplasmacytic infiltration in superficial cervical stroma (H\&E, x40, A) Chronic nonspecific cervicitis showing p16INK4A negativity (score-0, IHC, x40, B).

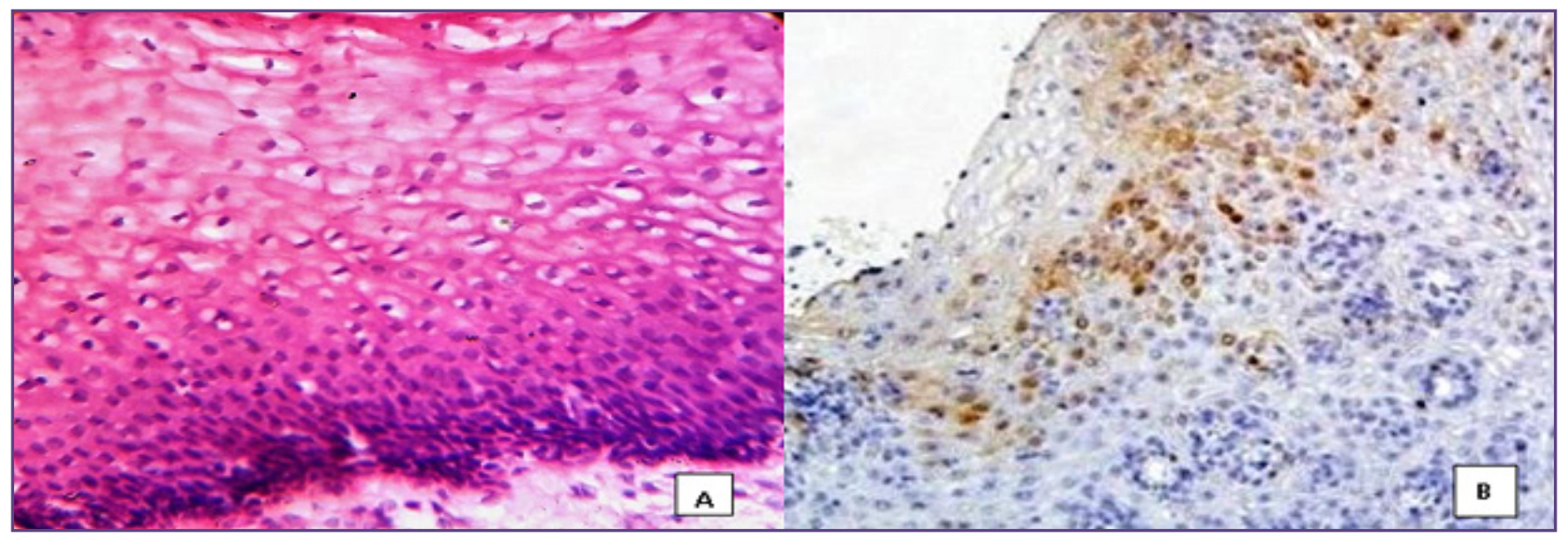

Fig. 3: Low grade squamous intraepithelial lesion showing dysplastic cells involving lower third of cervical epithelium and koilocytes in middle layer (H\&E, x40, A) Low grade squamous intraepithelial lesion showing p16INK4A nuclear and cytoplasmic positivity in lower one third of cervical epithelium (score-1, IHC, x40, B). 


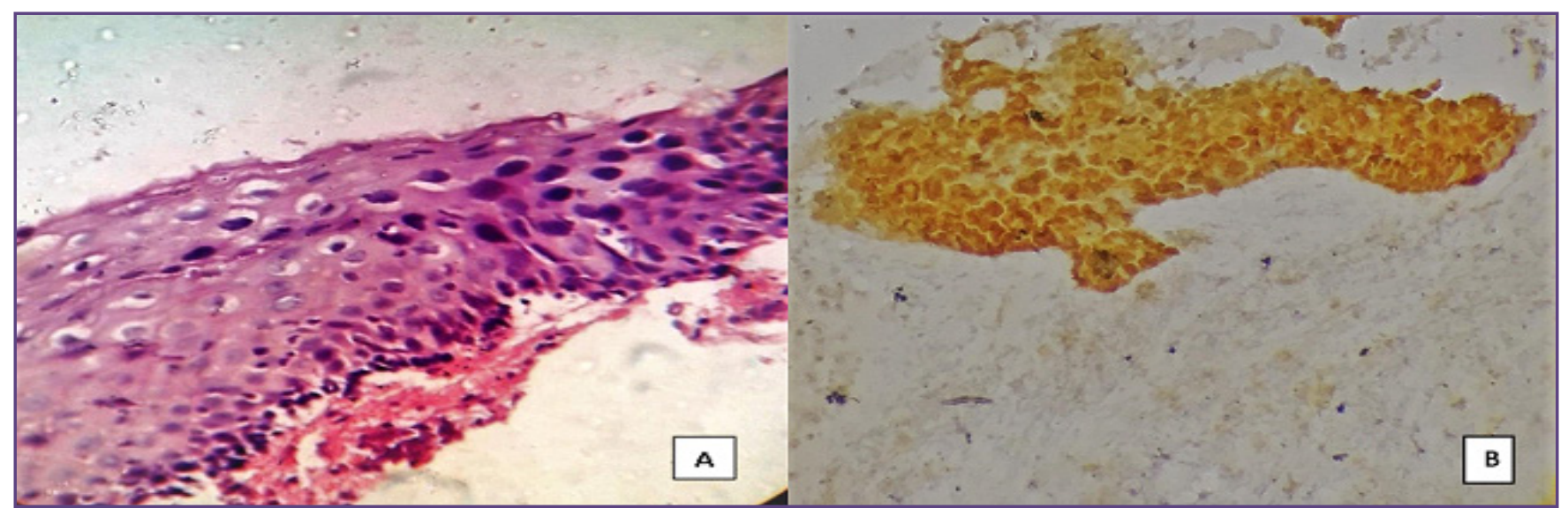

Fig. 4: High grade squamous intraepithelial lesion showing dysplastic cells involving full thickness of cervical epithelium (H\&E, x40, A) High grade squamous intraepithelial lesion showing p16INK4A nuclear and cytoplasmic positivity in full thickness of cervical epithelium (score-3, IHC, x40, B).

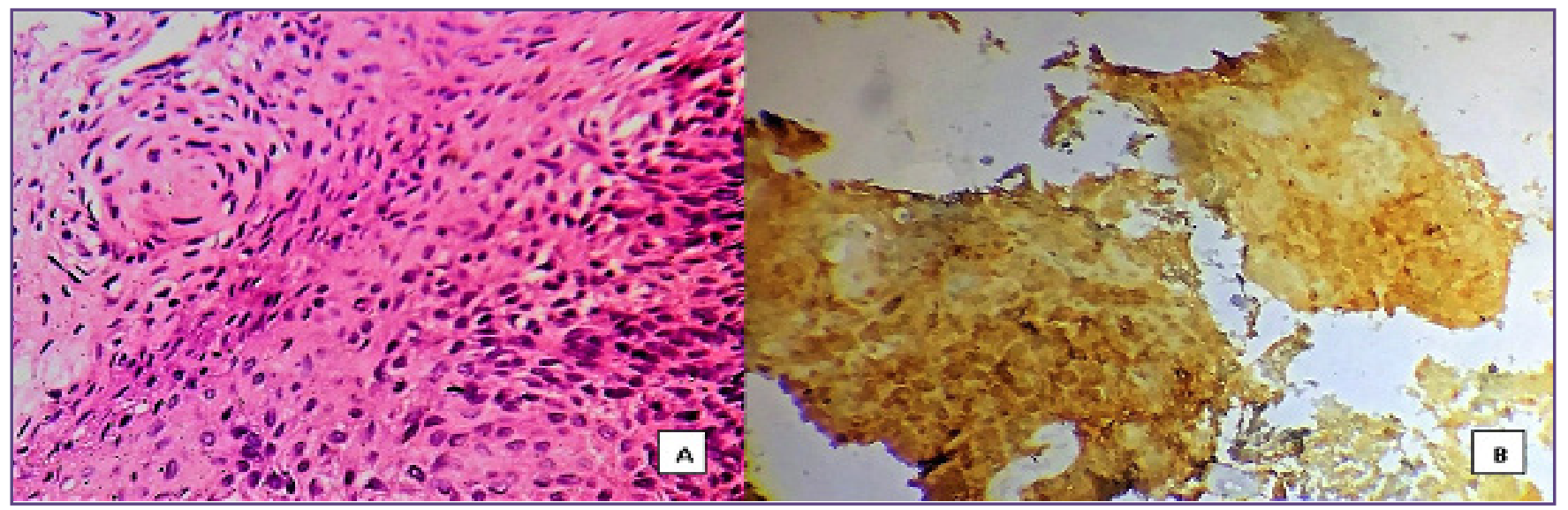

Fig. 5: Squamous cell carcinoma cervix showing sheets of malignant squamous cells showing mitotic figures (H\&E, $\mathrm{x} 40$, A) Squamous Cell Carcinoma showing p16INK4A nuclear and cytoplasmic positivity in sheets of malignant cervical epithelium (score -3, IHC, x40, B).

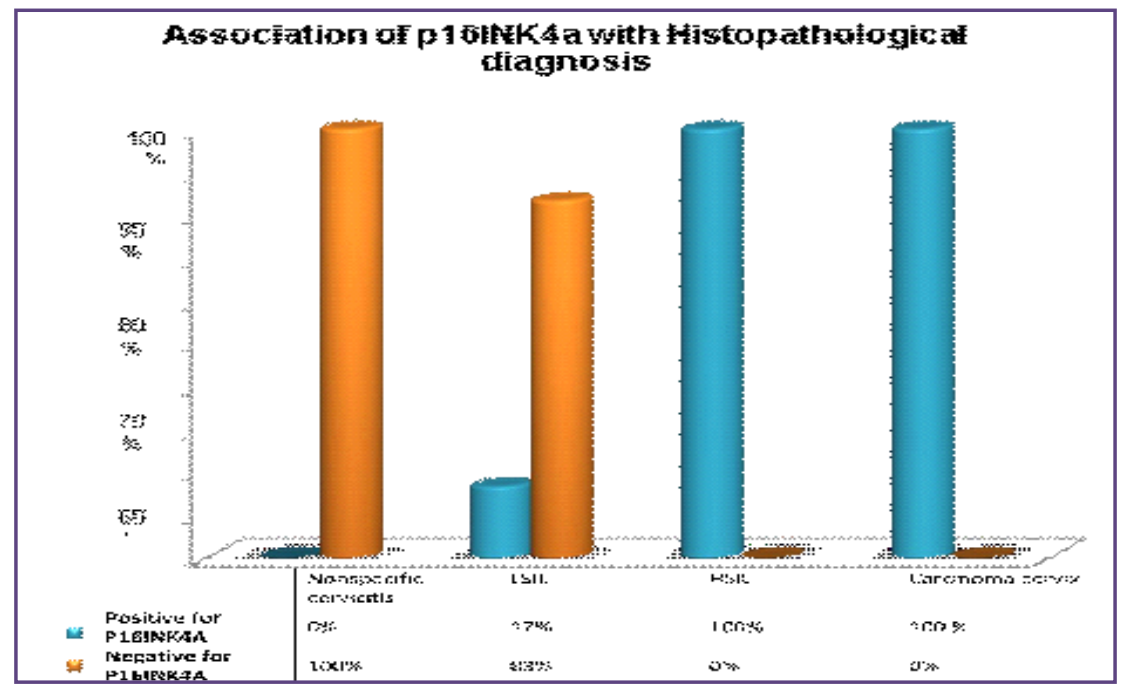

Fig. 6: Association of p16INK4A expression in different cervical lesions. 


\section{Discussion}

In the present study, the immunohistochemical expression of p16INK4A, a cyclin dependent kinase inhibitor in benign, premalignant and malignant lesion of uterine cervix were assessed by the intensity and proportion of staining by cervical tumor cells. $100 \%$ (28 out of 28 ) cases of the cervical squamous cell carcinoma showed strong nuclear and cytoplasmic positivity for p16INK4A. Similar findings were observed in the study done by Reuschenbach et al. ${ }^{[14]}$ Agoff et al also reported $92 \%$ (42 out of 46) of cervical carcinoma cases with nuclear and cytoplasmic positivity for p16INK4A. ${ }^{[15]}$

All 12 high grade squamous intraepithelial lesion cases showed $100 \%$ positivity for 16 INK 4 A. These findings are in accordance with the similar studies by Fatemah et al ${ }^{[16]}$ and Reuschenbach et al. ${ }^{[14]} \mathrm{Hu} \mathrm{L}$ et al also reported 100\% positivity in CIN 3 cases. ${ }^{[17]}$

In this study, out of 12 low grade squamous intraepithelial lesion cases, only two (16.7\%) were positive for p16INK $4 \mathrm{~A}$ in less than $33 \%$ of epithelial cells 9 [score 1]. In the study done by Agoff et al, $8 \%$ of cases showed positivity for p16INK4A in less than $25 \%$ of epithelial cells and vatsala et al ${ }^{[18]}$ also reported $25 \%$ of LSIL cases positive for p16INK4A expression.

All cases of nonspecific cervicitis cases showed no expression of p16INK4A in this study. Similar findings were noticed in the study done by Munhoz et al ${ }^{[19]}$ and $98.2 \%$ cases showed lack of expression of p16ink $4 \mathrm{~A}$ in the study done by Fatemeh sari et al ${ }^{[16]}$

All cases of Squamous cell carcinoma and HSIL showed an over -expression of p16INK4A. Similar evidence were obtained by the studies done by Benevolo et al and Volgareva et al ${ }^{[20,21]}$.[Table 3] This reflects the close association of overexpression of p16INK4A in HSIL and Squamous cell carcinoma with the degree of premalignancy and malignancy and its pivotal role in the progression of malignancy in cervix.

In this prospective study, Allred scoring analysis demonstrated a graded increase in the expression of the protein p16 INK4a from nonspecific cervicitis to LSIL and further to HSIL and invasive squamous cell carcinoma with $\mathrm{p}$ value of less than 0.05 . Hence it was found that there is an increase of p16INK4A according to the increase in dysplastic cells that indirectly indicates the degree of premalignancy and malignancy. Thus, expression of p16INK4A protein in cervical biopsies can serve as a specific marker for diagnosing premalignant and malignant lesions.
Moreover our study in benign lesions like nonspecific cervicitis showed no expression of $\mathrm{p} 16 \mathrm{INK} 4 \mathrm{~A}$ as compared to premalignant(LSIL-17\% and HSIL- $100 \%$ positive) and malignant lesions (100\% positive). Hence p16INK4A can be used as an adjunct tool to distinguish benign lesions from premalignant and malignant lesions to enhance the diagnostic accuracy. This fact could help in the differential diagnosis between the cervical lesions.

\section{Conclusion}

This prospective study of one year duration was conducted to assess the expression of marker p16INK4A in benign, premalignant and malignant cervical lesions and its role in diagnosis. This study showed no expression of p16INK4A protein in all cases of Nonspecific cervicitis, 17\% LSIL cases showed strong nuclear and cytoplasmic p16INK4A positivity with score 1. p16INK4A expression in HSIL was positive in all with each $17 \%$ cases of score 1 and 2 and $66 \%$ cases of score 3 . Invasive squamous cell carcinoma of cervix showed p16INK4A expression in all cases with $14.3 \%$ cases of score 2 and $85.7 \%$ cases of score 3 . It showed the upregulated expression of p16INK4A protein from benign to premalignant and to malignant lesions of uterine cervix. Hence it was found that there is an increase of p16INK4A according to the increase in dysplastic cells that indirectly indicates the degree of premalignancy and malignancy.

Histopathological examination is considered as a gold standard method for diagnosis of cervical lesions. p16INK4A marker can be used as an adjunct diagnostic tool in the differential diagnosis of cervical intraepithelial lesion for resolving uncertain morphologies to enhance the accuracy in diagnosis. From this study, we found that p16INK4A played the defining role in early detection of cervical cancer.

\section{Acknowledgements}

Nil

\section{Funding}

Nil

\section{Competing Interests}

No

\section{Reference}

1. Bray F, Ferlay J, Soerjomataram I, Siegel RL, Torre LA, Jemal A. Global Cancer Statistics 2018.Retrieved from https://www.wcrf.org/dietandcancer/cancer-trends/cervicalcancer-statistics.

2. Kaarthigeyan K.Indian J med Paediatr Oncol.2012 JanMar;33(1):7-12. 
3. Denny L. Cervical cancer: prevention and treatment.Discov Med.2012;14:125-131

4. Schiffman M,Castle PE,Jeronimo J,et al:Human papilloma virus and cervical cancer.Lancet 370:890,2007

5. Queiroz C, Silva TC, Alves VAF, et al. P16(INK4a) expression as potential prognostic marker in cervical preneoplastic and neoplastic lesions. Pathol Pract Res 2006; 202: 77- 83 .

6. Keating JT, Cviko A, Riethdorf S, et al. Ki-67, cyclin E, and p16INK4 are complementary surrogate biomarkers for human papillomavirus related cervical neoplasia. Am J Surg Pathol 2001; 25(7): 884-91.

7. Jiang, et al. Prognostic value of p16 expression in Epstein Bar Virus positive nasopharyngeal carcinomas. Head Neck. 2016 Apr

8. Branca M, Ciotti M, Santini D, et al. P16 (INK4A) expression is related to grade of cin and high-risk human papillomavirus but does not predict virus clearance after conization or disease outcome. Int J Gynecol Pathol 2004; 23(4): 354-65.

9. Bahnassy AA, Zekri ARN, Saleh M, Lotayef M, Moneir $\mathrm{M}$, Shawki O. The possible role of cell cycle regulators in multistep process of HPVassociated cervical carcinoma. BMC Clin Pathol 2007; 7: 4.

10. George L.Mutter,Jaime Prat., "Cervical benign and non neoplastic lesions," Pathology of the female genital tract,2 nd edition, pp. 170,2009.

11. George L.Mutter,Jaime Prat., “ Biology of cervical squamous neoplasia," Pathology of the female genital tract,2 nd edition, pp. 191,2009.

12. Well M,Ostor AG,Franceshi S et al.Epithelial tumours of the uterine cervix.In: Tavassoli FA,Devilee P,editors.Tumors of the breast and female genital organs.LONS,France:IARC Press;2003.p.221-32.

13. Mahdieh Farzanehpour et al. P16INK4A Immunohistochemistry as a Gold standard for Cervical
Cancer and Precursor Lesions Screening Iran J Public Health, Vol. 49, No.2, Feb 2020, pp.312-322

14. Miriam Reuschenbach1, Mirjam Seiz1, Christina von Knebel Doeberitz1, Svetlana Vinokurova1, Alexander Duwe2,Ruediger Ridder2, Heike Sartor1, Friedrich Kommoss3, Dietmar Schmidt3 and Magnus von Knebel Doeberitz, Evaluation of cervical cone biopsies for coexpression of p 16INK4a and Ki-67 in epithelial cells, Int. J. Cancer: 130, 388-394 (2012).

15. S. Nicholas Agoff, M.D., Patricia Lin, M.P.H., Janice Morihara, B.S., Constance Mao, M.D.,Nancy B. Kiviat, M.D., Laura A. Koutsky, Ph.D: p16INK4a Expression Correlates with Degree of Cervical Neoplasia. A Comparison with Ki-67 Expression and Detection of High-Risk HPV Types Mod Pathol 2003;16(7):665-673.

16. Fatemeh Sari Aslani et al. Cell cycle and/or proliferation markers: What is the best method to discriminate cervical high-grade lesions,Hum Pathol 2005; 36 : 1101-7.

17. Hu L, Guo M, He Z, Thornton J, Mcdaniel LS, Hughson MD. Human papilloma virus genotyping and p16ink4a expression in cervical intraepithelial neoplasia of adolescents. Mod Pathol. 2005;18:267-73

18. Kishore, Vatsala, and Anuradha G Patil. "Expression of p16INK4A Protein in Cervical Intraepithelial Neoplasia and Invasive Carcinoma of Uterine Cervix." Journal of clinical and diagnostic research : JCDR vol. 11,9 (2017): EC17EC20. doi:10.7860/JCDR/2017/29394.10644

19. Natália Gaspar Munhoz, Damaris Aparecida Rodrigues et al, The Use of Molecular Markers (p16, Ki-67 and E-Cadherin) in Uterine Cervical Biopsies, The Open Pathology Journal, 2009, 3, 10-17.

20. Benevolo M, Mottolese M, Marandino F, et al. Immunohistochemical expression of p16(INK4a) is predictive of HR-HPV infection in cervical low-grade lesions. Mod Pathol 2006; 19(3): 384-91.

21. Volgareva G, Zavalishina L, Andreeva Y, et al. Protein p16 as a marker of dysplastic and neoplastic alterations in cervical epithelial cells. BMC Cancer 2004; 4: 58.

*Corresponding author:

Shivapriya R, 402, ICC Diya Apartment, GRG Chandra Gandhi Nagar, Peelamedu, Coimbatore, India

Phone: +91 9629367976

Email: shivapriyadivakar@gmail.com

Date of Submission : 29/06/2020

Date of Acceptance : 10/09/2020

Financial or other Competing Interests: None.
Date of Publication : 30/10/2020 